\title{
Vibration Detection Using Optical Fiber Sensors
}

\author{
Yoany Rodríguez García, ${ }^{1}$ Jesús M. Corres, ${ }^{2}$ and Javier Goicoechea ${ }^{2}$ \\ ${ }^{1}$ Telecommunication Department, Pinar del Río University, Av. Martí 270, Pinar del Río, Cuba \\ ${ }^{2}$ Electric and Electronic Engineering Department, Edif. Los Tejos, Campus Arrosadia, Public University of Navarra, \\ 31006 Pamplona, Spain \\ Correspondence should be addressed to Yoany Rodríguez García, yoany79@gmail.com
}

Received 1 March 2010; Revised 24 May 2010; Accepted 5 July 2010

Academic Editor: Ignacio Matias

Copyright ( $) 2010$ Yoany Rodríguez García et al. This is an open access article distributed under the Creative Commons Attribution License, which permits unrestricted use, distribution, and reproduction in any medium, provided the original work is properly cited.

Condition monitoring of heavy electromechanical equipment is commonly accomplished in the industry using vibration analysis. Several techniques, mainly based on capacitive and piezoelectric accelerometers, have been applied for predictive maintenance. However, the negative influence of the electromagnetic interference (EMI) can be a real problem when electrical signals are used to detect and transmit physical parameters in noisy environments such as electric power generator plants with high levels of EMI. Optical fiber sensors are increasingly used because of the nonelectrical nature of signals. In this paper, the most frequently used vibration optical fiber sensors will be reviewed, classifying them by the sensing techniques and measurement principles. The main techniques, intensity modulation, fiber bragg gratings and Fabry-Pérot Interferometry, will be reviewed here.

\section{Introduction}

Since a few decades ago, fiber optic sensors technology has experimented a revolution by the hand of fiber optic telecommunication product outgrowths with optoelectronic devices [1-4]. These new areas of opportunities include the potential of replacing the majority of environmental sensors in existence today, as well as opening up entire markets where sensors with comparable capability do not exist. These new technologies, combined with advances in optical transducers, have enabled remote vibration monitoring using compact portable instrument packages in highly localized parts of electrical machinery with inherent electrical isolation, superior dielectric properties, and immunity to electromagnetic interference $[2,3]$. In addition, optical fiber sensors can offer noncontact, perturbation-free means of monitoring as they provide a new approach to vibration monitoring in electromechanical equipment.

Fiber optic sensors can be generally classified in two groups: extrinsic (fiber optic sensors distinguished by the characteristic that sensing takes place in a region outside the fiber) and intrinsic (fiber optic sensors characterized by the fact that sensing takes place within the fiber itself) [49]. However, optical fiber sensors also can be classified by their working principles. In Figure 1 a general classification of vibration sensors is shown: intensity-based sensors (IBSs) are those in which intensity is modulated by an external parameter; Fabry-Pérot interferometers (FPIs) are passive optical structures that utilize multiple-beam interference in a cavity between two semireflective surfaces. Fiber bragg gratings (FBG) are fabricated using a longitudinal periodic perturbation of the refractive index of the core of an optical fiber. In this paper this three measurement principles will be analyzed.

\section{Intensity-Based Vibration Sensors}

Intensity-based sensor techniques have been studied and implemented in the last 25 years (see Figure 2). A wide range of configurations can be used, such as fiber microbending, fiber-to-fiber coupling, moving masks/gratings, and modified cladding [6, 10-17].

These sensors can be classified into two broad categories if physical contact with the vibrating object exists or not. Usually noncontact structures use a reflective signal to detect displacement or vibration while the other structures (i.e., microbending) use the transmissive configuration. 
As a general rule, in the intensity-based sensor structure the light intensity from the source is modulated by the transducing device; then it is guided to the detector, translated to electronic signals, and adequately processed [9] as shown in Figure 3.

In many cases, it is necessary to have a referencing mechanism in order to maintain the sensor calibrated. Without this referencing mechanism, optical power fluctuations due to the source, couplers, connectors, or any other optical components in the system can introduce significant relative errors. In some cases, digital communication techniques such as code division multiple access (CDMA) or spread spectrum techniques (SSTs) can reduce noise impact $[6,10$ $15]$.

2.1. Microbend Structure. The microbend sensor was one of the earliest Intensity-based sensors to be developed [16-18]. The detection principle is based on the change of transmitted power as a function of pressure/stress. Basically, in this structure, the light intensity decreases by the losses caused by the induced microcurvatures (see Figure 4 ).

The deformation causes a coupling of the optical power from the core-guided modes to higher order radiation modes; these modes are attenuated by the surrounding medium.

Both multimode and single-mode fibers have been used for the constructions of these sensors [19]. While multimode microbend sensors show the maximum sensitivity when the bending frequency is equal to the difference in propagation constants for the propagating and radiation modes [20], in single-mode optical fiber microbend sensors, the maximum sensitivity is achieved when the spatial bend frequency equals the difference between the propagation constants of the fundamental mode and a discrete cladding mode [21].

An example of this technique has been reported by Pandey and Yadav in [22]. They used a microbending sensor placed into a construction panel to detect pressure and deformation. The calibration of this sensor was made in laboratory conditions, therefore the output optical power was directly related with the pressure applied to the sensor, see Figure 5.

2.2. Noncontact Displacement Intensity-Based Sensor. Noncontact dynamic displacement sensors are commonly used for vibration detection. A reflective scheme is used to detect vibrations where one fiber is used as an emitter source and one or more fibers are used as collectors (Figure 6). The reflection from the surrounding surfaces near the target can be minimized using data treatment techniques $[10,12]$.

An example of this configuration is shown in Figure 7. Binu et al. [23] developed a simple, rugged, and low-cost noncontact IBS using two PMMA cemented fibers. The main advantage of this configuration is the low cost of fabrication of the sensor and transducer.

However, although intensity-based fiber optic sensors are easy to build, a significant error can be introduced due to changes in the light source power. Losses due to physical configuration and reflective surfaces outside of the measure system often impact the final measurement accuracy. Fortunately, referencing for source-intensity fluctuations is relatively easy to implement

Recently, Perrone and Vallan [12] presented a highresolution and cheap optical sensor (using plastic optical fibers) to measure vibrations of up to several tens of $\mathrm{KHz}$ by using an intensity-detection scheme followed by a nondemanding data processing to compensate for the vibrating surface reflectivity and measurement chain gains. In this sensor, one fiber is used to transmit the light whereas the other fiber collects the light rejected by the target whose vibrations $s(t)$ have to be measured. The received signal is processing after the photo detector conversion. The experimental setup used by Perrone et al. is shown in Figure 8.

Those intensity-based sensors are usually low cost and versatile structures. Even the particular in reflective experimental setups of those sensors allows them to be used in noncontact applications.

\section{Fabry-Pérot Interferometers}

Fabry-Pérot interferometers are optical structures that utilize multiple-beam interference in a cavity between two semireflective surfaces.

In the last three decades, a lot of applications of this structure have been developed, supported by an extraordinary explosion of optical communication and the use of optical fiber as transmission guide and measurement material. The evolution of this optical structure as vibration sensor can be seen in Figure 9.

The basic structure of the Fabry-Pérot optical sensors is based in two plane and parallel surfaces with partial reflectivity so that multiple rays of light are responsible for creation of the observed interference patterns.

In order to obtain an in-fiber Fabry Pérot sensor (IFFPI) partial mirror-surfaces have to be created inside the fiber, as shown Figure 10. This sensor can be built by using chemical processes or by fusion currents.

The general theory behind the other interferometers still applies to the Fabry-Pérot model; however, these multiple reflections reinforce the areas where constructive and destructive effects occur making the resulting fringes much more clearly defined [31-34].

The reflectance ratio of reflected irradiance $I_{r}$ to incident irradiance $I_{i}$ is periodic with the round-trip phase $\varphi$, difference between beams, as shown in

$$
\frac{I_{r}}{I_{i}}=\frac{F \sin ^{2}(\varphi / 2)}{1+F \sin ^{2}(\varphi / 2)},
$$

where the surface reflectivity $R$ of the cavity surfaces determines the cavity finesse $F$.

The finesse is defined as

$$
F=\frac{4 R}{(1-R)^{2}} .
$$




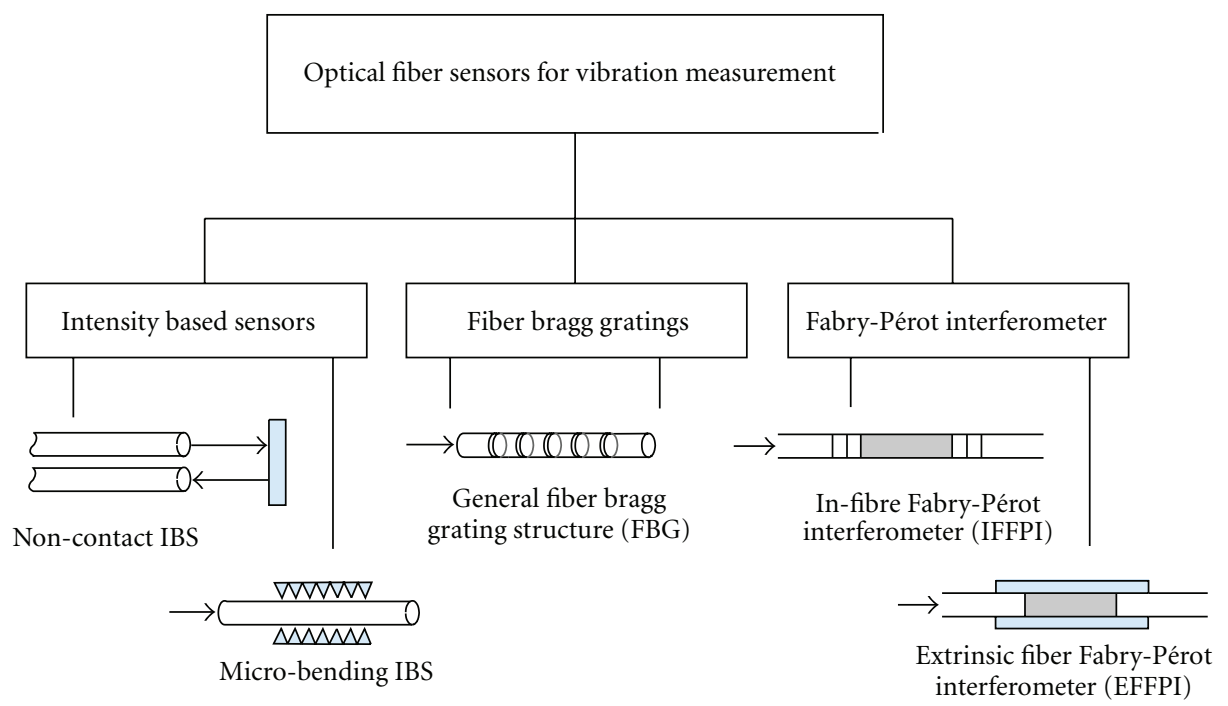

Figure 1: Vibration optical fiber sensors classification.

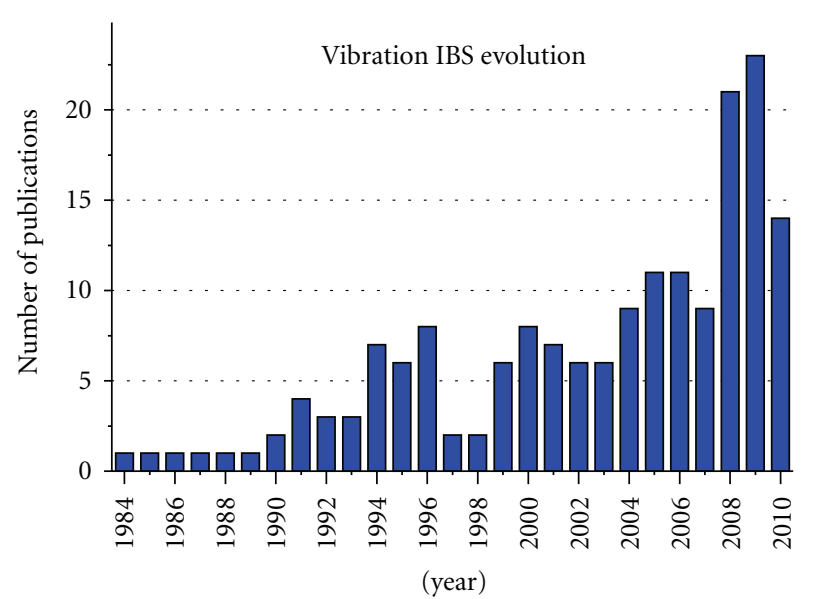

FIGURE 2: Evolution of vibration intensity-based sensor, (source database: Scopus).

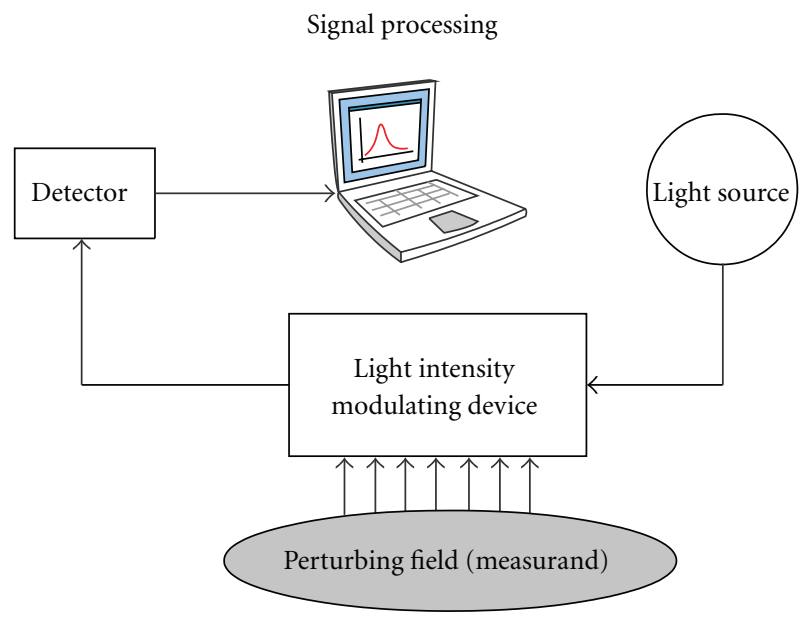

FIgURE 3: Configuration for intensity modulation systems.

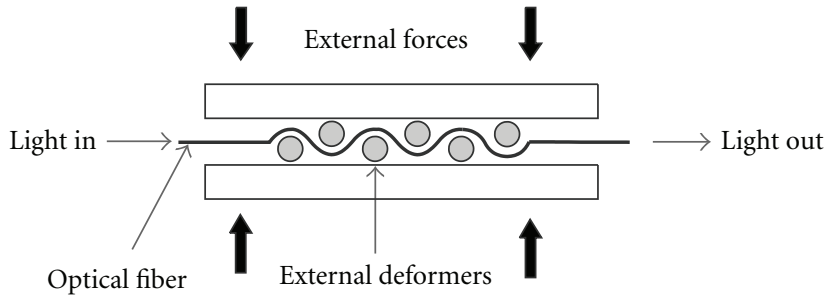

FIgURE 4: Microbends sensor structure.

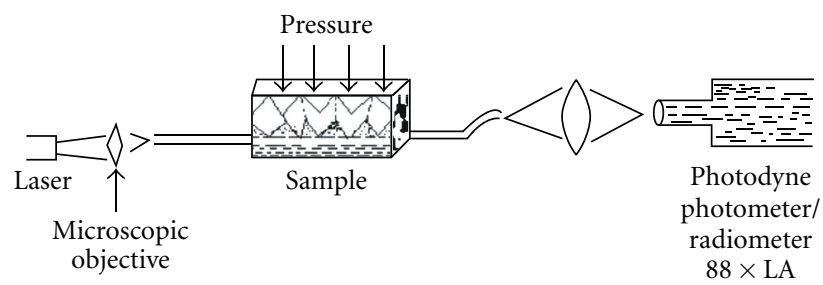

Figure 5: Setup of embedded fiber-optic microbend sensor for measurement of high pressure and crack detection. (reproduced from [22] with permission of Elsevier).

Many of these interferometers suffer the common problem of directional ambiguity in fringe motion when the measured target changes direction since the output interference signals are cosinusoidal in nature $[35,36]$. General solutions include additional or multiple interrogating cavities, multiple wavelength and quadrature phase-shifting techniques. The interference fringes are detected as an electrical signal and feedback into a comparator circuit to generate the desired quadrature condition.

In extrinsic version of the Fabry-Pérot interferometer (EFFPI), the optical cavity is external to the fiber [37-40]. The alignment of the fiber end faces is maintained by a bonded capillary tube or can be placed one in front of the other. In this case, a coherent source is necessary to avoid 


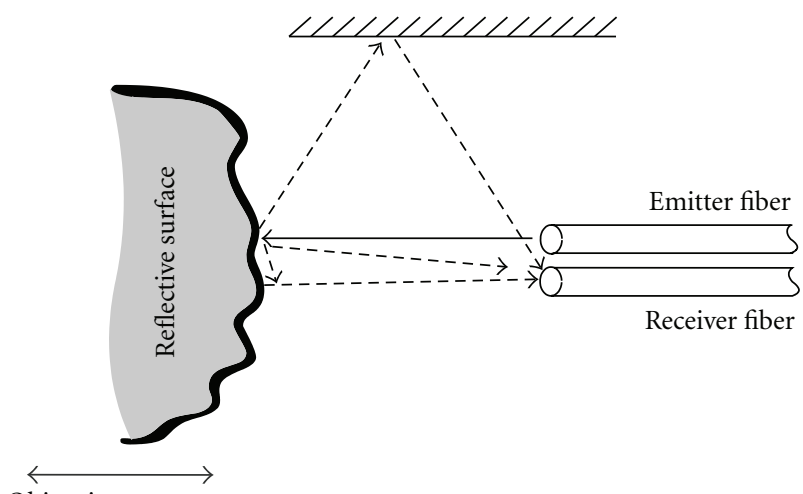

Object in movement

FIGURE 6: Configuration for dynamic displacement intensity-based sensor.

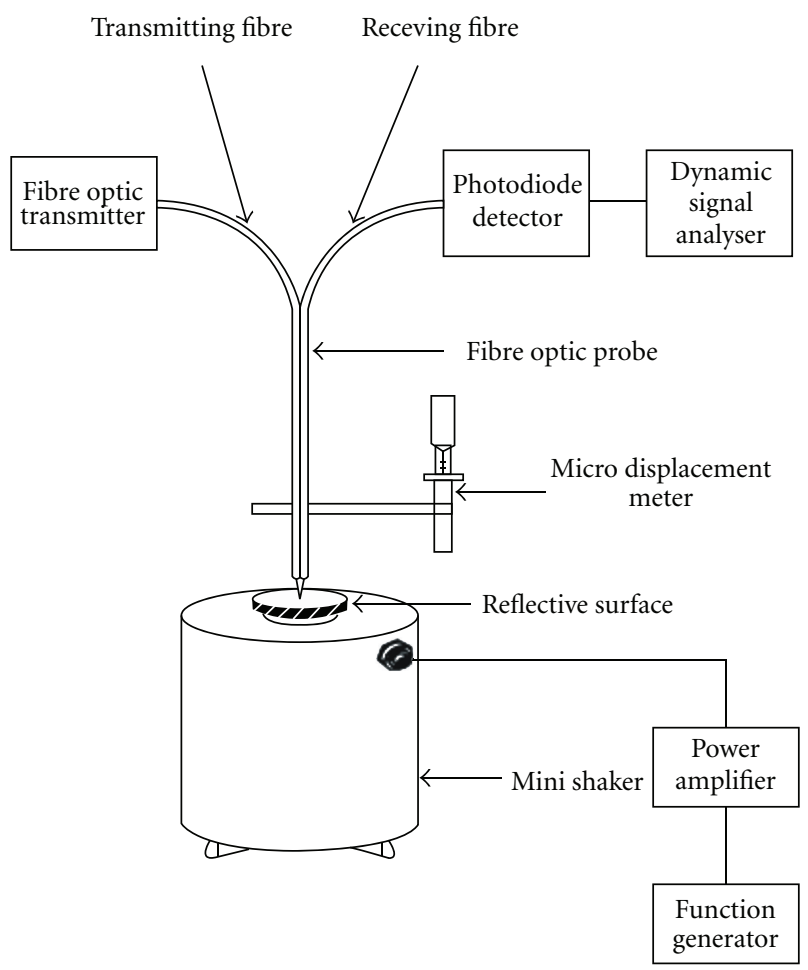

Figure 7: Schematic experimental setup of fiber optic displacement sensor for the measurement of vibrational frequency (reproduced from [23] with permission of Elsevier).

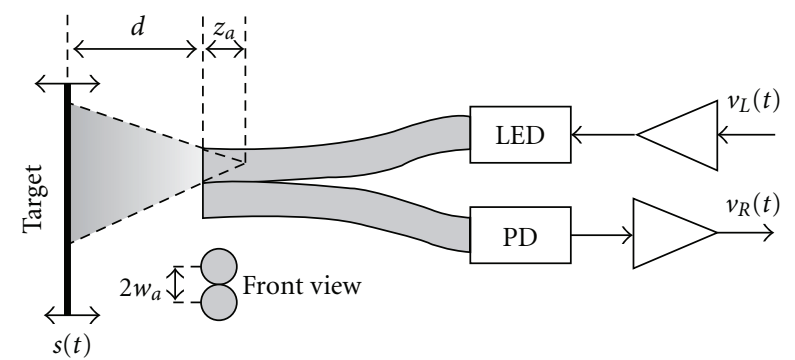

Figure 8: Plastic optical fiber sensor setup [12].

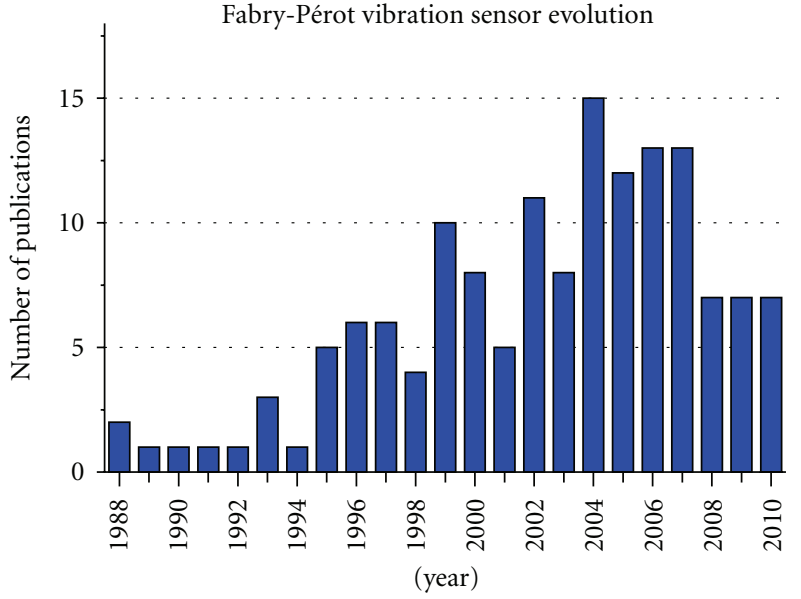

Figure 9: Evolution of Fabry-Pérot vibrations sensors (source database: Scopus).

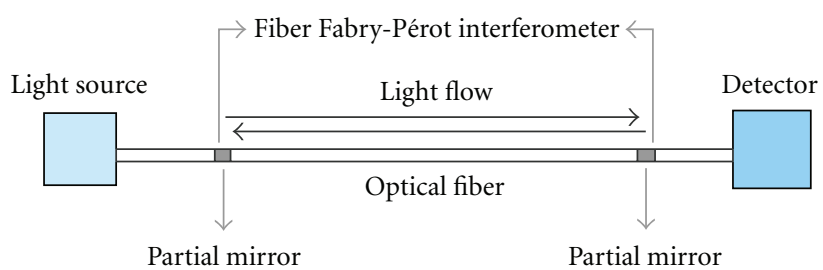

Figure 10: General structure of in-fiber Fabry-Pérot interferometers.

excessive power losses. As the substrate and the attached tube are strained, the reflected interference signal varies in response to the changes in cavity spacing (see Figure 11).

More sophisticated configurations of extraordinary sensitivity have been developed using fiber brag gratings working as mirrors [41]. In the next sections several selected examples will be analyzed.

\subsection{Extrinsic Fiber Fabry Pérot Interferometer Vibrations} Sensors. Although multiple sensor applications have been reported using the FPI sensor signals directly, as it has been previously described, some other applications can be significantly improved using signal processing techniques in the electrical domain. One example of this is shown in Figure 12. In this structure, a configuration of multiple fringe and nonsinusoidal signals obtained from a fiber-optic vibration sensor using an extrinsic Fabry-Pérot Interferometer is presented by Gangopadhyay et al. [24]. In this configuration, a wavelength transform- (WT-) based signal processing methodology was employed to count optical fringes. WT-based tool was developed by the authors for unambiguous identification of frequency components from a nonsinusoidal vibration situation of multiple fringes and complex frequency measurements.

Some Fabry-Pérot sensors need to be previously calibrated prior to use, as it is described in [42]. In this work, it was showed a feasible method to calibrate the PVDF strain sensor using four points from the Bessel harmonics of a 


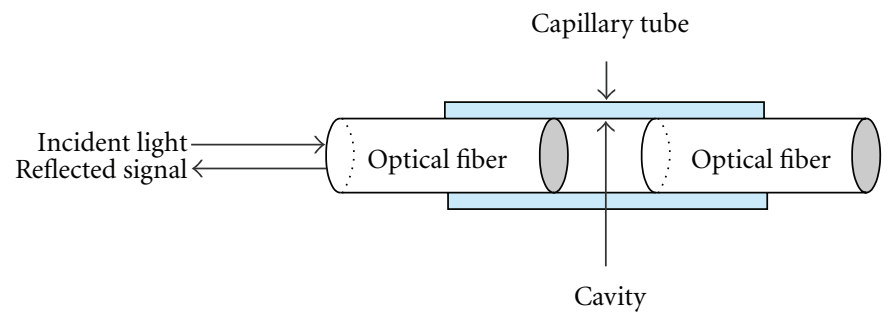

Figure 11: Extrinsic Fabry-Pérot interferometers, based in capillary tube.

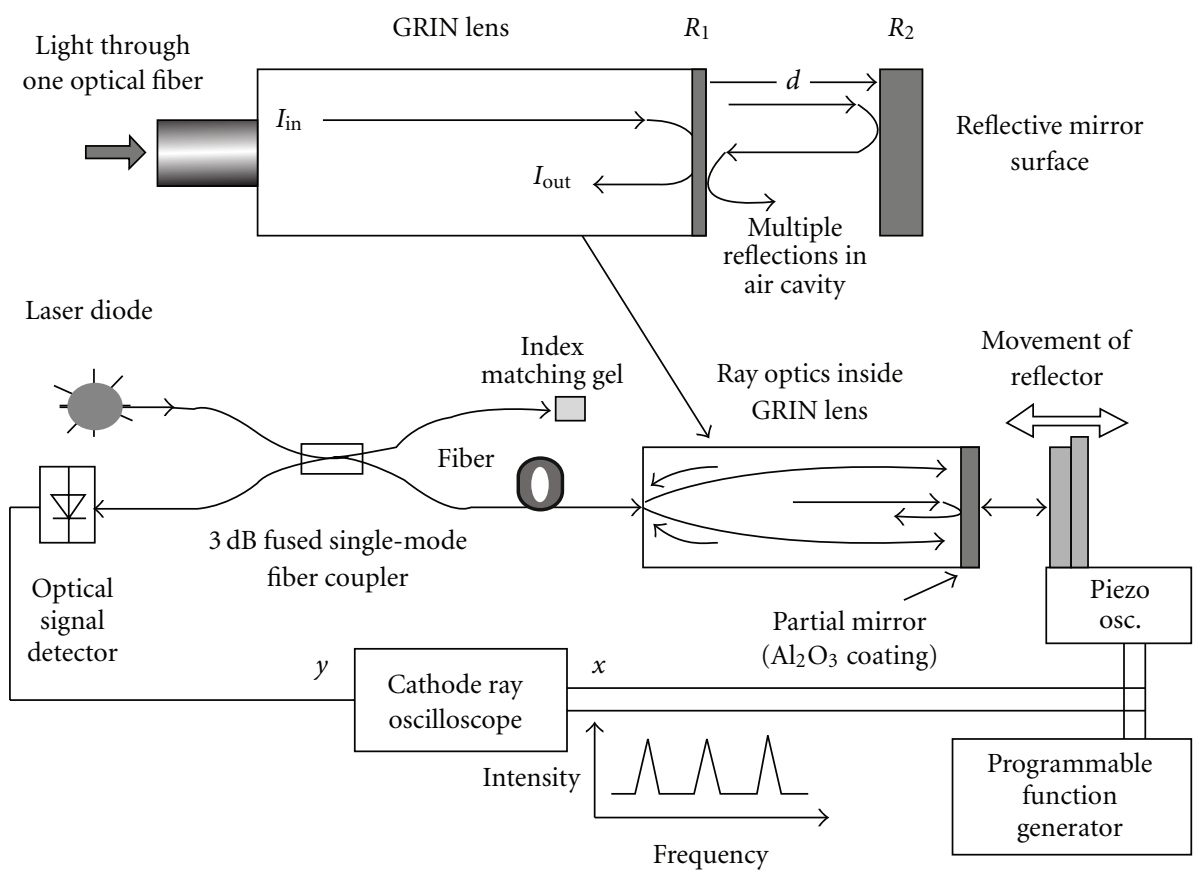

FIGURE 12: Schematic of a reflective EFPI sensor connected with one fiber and measurement system. (reproduced from [24] with permission of IEEE).

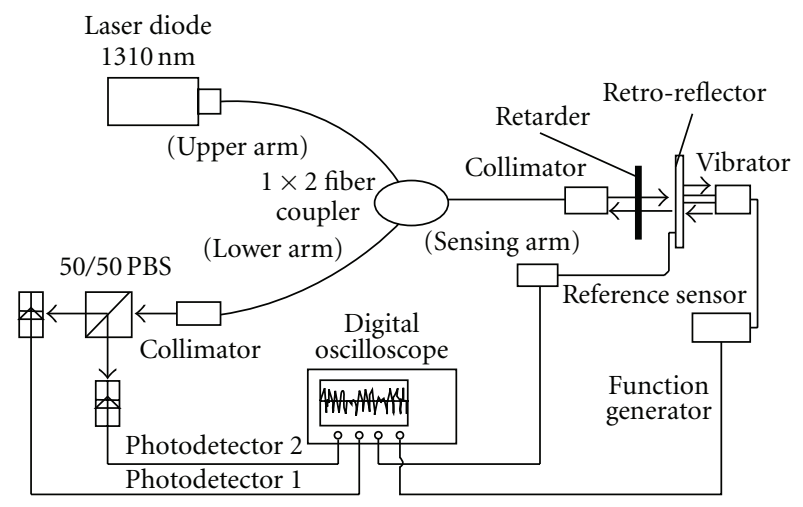

Figure 13: Schematic diagram of the dual-cavity fiber Fabry-Pérot interferometer for vibration analysis [25].

fiber optic EFPI sensor which did not required of complex demodulation schemes other than standard spectrum analyzer capability.
Pullteap et al. [25] presented a modified fringe-counting technique applied to a dual-cavity fiber Fabry-Pérot vibration meter. The scheme of the structure is shown in Figure 13, where continuous series of interference signals can be processed for fringe-counting. The main advantage of such a technique is the increased resolution, which can be obtained without further complicated signal processing schemes, because it allows calculating the crossover points and integrate the interference peaks in the algorithm due to the stable optically generated quadrature condition employed.

3.2. In-Fiber Fabry Pérot Interferometer Vibrations Sensors. One of the first applications of IFFPI was presented by Yoshino et al. [26]. In this implementation, detection of impact vibration was done using a single mode FFPI with $70 \%$ end-reflectance. A schematic diagram of the developed system is shown in Figure 14.

Other IFFPI application was reported in 1983 by Kersey et al. [43]. The experimental setup shown in Figure 15 is formed by a single-mode IFFPI with uncoated fiber ends. 


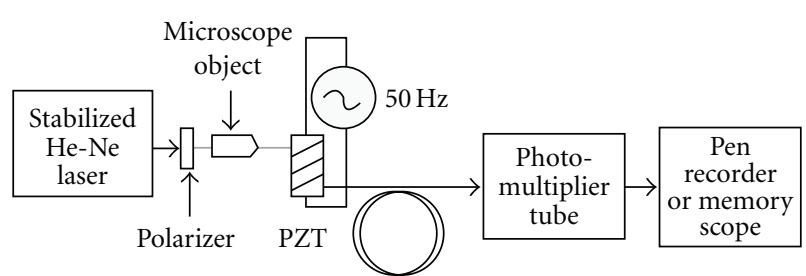

Figure 14: Fiber Fabry-Pérot interferometric for vibration detection. (reproduced from [9] with permission of Elsevier).

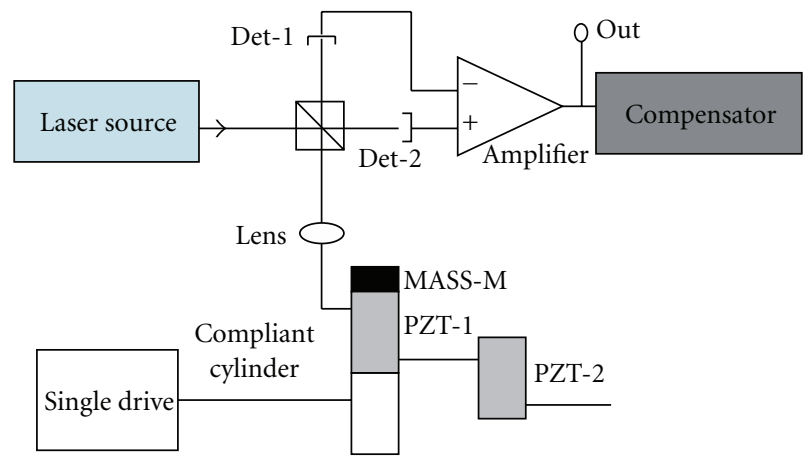

FIGURE 15: Setup of IFFPI with uncoated fibre ends as an accelerometer [26].

The system had a resonance peak as low as $150 \mathrm{~Hz}$ with a limiting sensitivity of $2 \times 10-7 \mathrm{~g}$.

Christmas et al. [44] presented an implementation of high-resolution vibrometers using wavelength demultiplexed fiber Fabry-Pérot sensors. The monitoring system is based on low-coherence interferometry [45]; see Figure 16. It consists of a Mach-Zehnder interrogating interferometer (MZI) and fiber Fabry-Pérot (FFP) sensors. The fiber Fabry-Pérot cavity is formed by a pair of fiber bragg gratings (FBGs) working as mirrors with a different reflectivity as a function of the wavelength. To enable constant sensitivity detection and the use of conventional RF signal recovery techniques, heterodyning signal processing was adopted.

Another IFFP sensor is formed by two portions of single mode fibers (SMF) fused to be a hole-core fiber (HCF) forming a Fabry-Pérot cavity being the end of each SMF the mirrors of the interferometer $[9,27,36]$; this structure is known as In-line Fiber Etalon or ILFE, Figure 17.

Several applications have been developed using the principle of Fabry-Pérot applied to ILFE. The equation that governs this structure shows the relationship between the optical reflected power and cavity deformation

$$
R_{D H}=A *\left[1+V * \cos \frac{4 \pi * L * \varepsilon}{\lambda}\right],
$$

where $A$ and $V$ are constants that represent the amplitude and visibility of the sensor, $\lambda$ is the wavelength of the optical source, $L$ is the cavity length, and $\varepsilon$ is the unitary deformation of the cavity [27].

Using this scheme, in [27], it was demonstrated that it can be applied for the detection of steady state performance

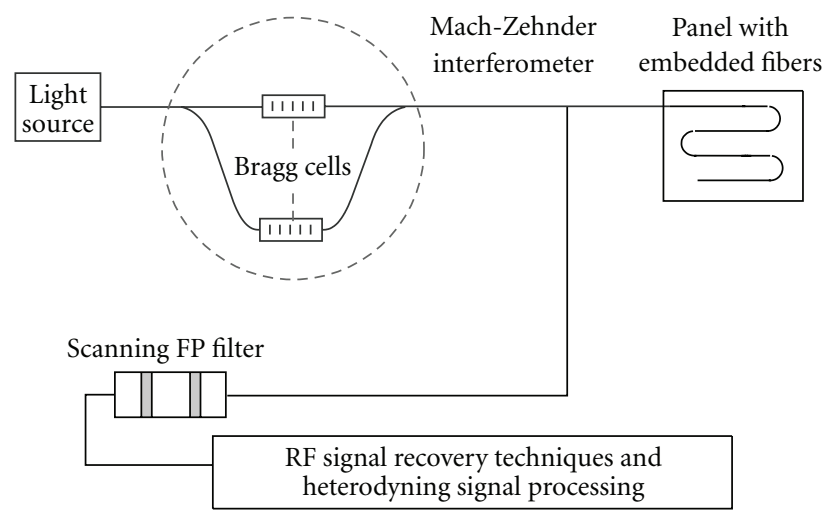

FIGURE 16: Schematic of high resolution vibration measurements using wavelength demultiplexed fiber Fabry-Pérot sensors.

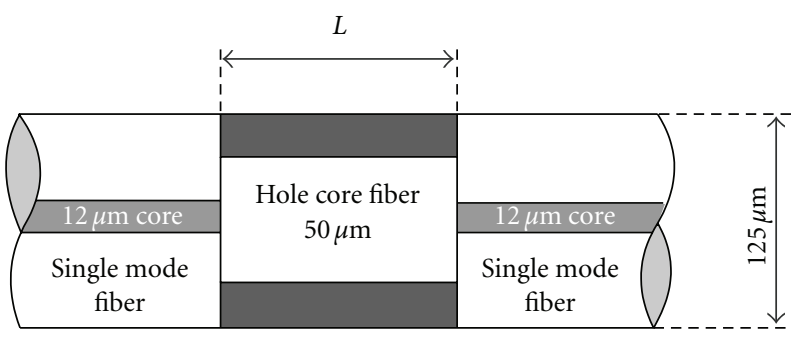

FIGURe 17: Fabry-Pérot interferometer formed by two SMF and a HCF, known as in-line etalon fiber (ILFE).

of three phase motors under unbalanced conditions, see Figure 18. This implementation showed the ILFE working as a spring and its deformation was registered using interferometry of the light reflected by the mirrors of a FabryPérot etalon. The photo-detector output was connected to an oscilloscope with a FFT module to show the vibration spectrum.

Fabry-Pérot interferometer provides high precision when measuring real-time surface vibrations. Some techniques such as wavelength division and transmitted and received optical signal can be used to obtain excellent relation with displacement, strain and vibration measurement.

Fabry-Pérot interferometer can be classified as one of the most sensitive structures in the area of optical fiber sensors. In this section, we have tried to show the wide range of experimental setups and applications that can be achieved using this optical structure. The main issues that can affect this structure are related to the fabrication of the mirrors, whose imperfections and alignment errors can reduce the sensor accuracy.

\section{Fiber Bragg Grating Sensors}

Fiber bragg gratings (FGBs) are optical fiber devices that consist in a longitudinal periodic perturbation of the refractive index of the core of an optical fiber. Such periodic variation of the optical properties of the fiber confers to it unique optical properties that make these devices ideal for optical sensing applications. In fact, since the first permanent 


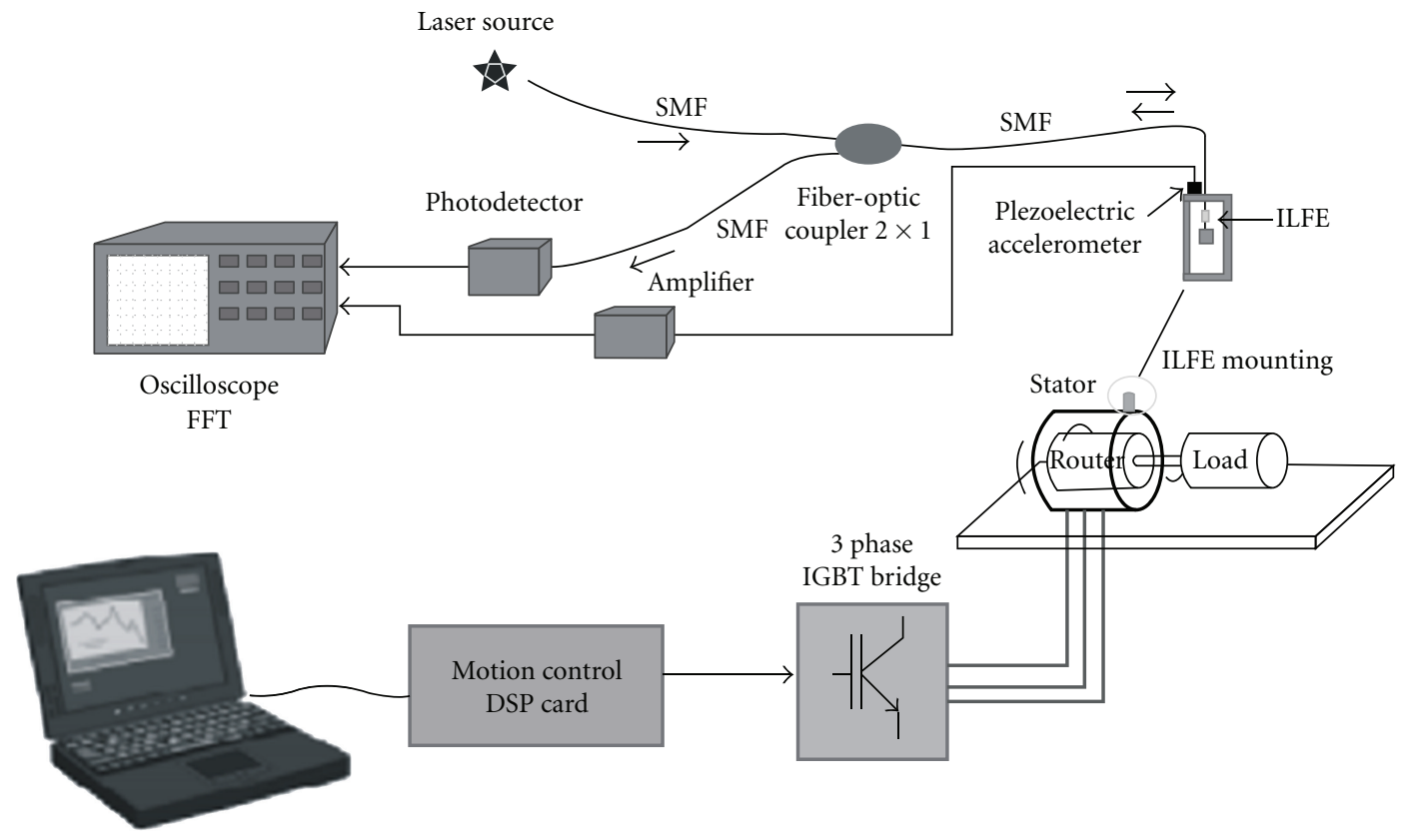

FIGURE 18: Schematic diagram of the transducer calibration system using in-line etalon fiber, (ILFE) (reproduced from [27] with permission of IEEE).

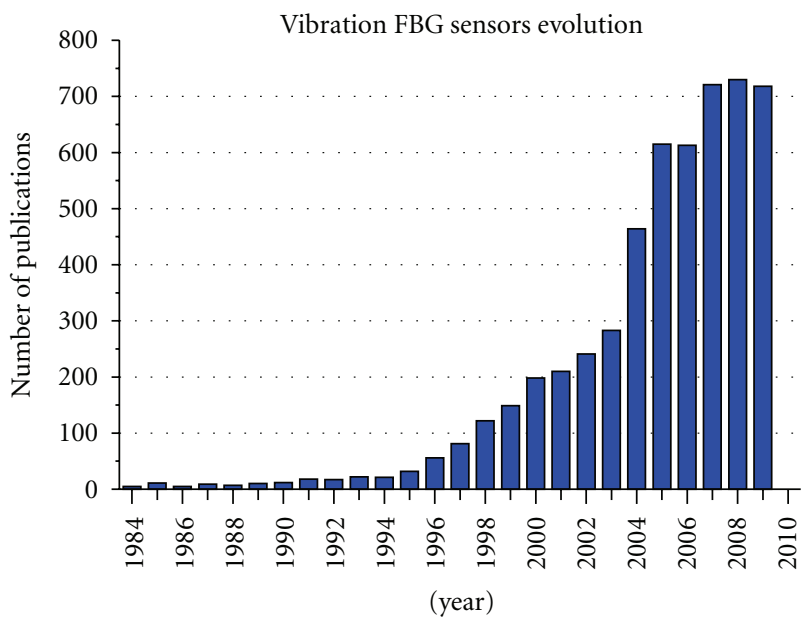

FIGURE 19: Evolution of FBG vibration sensors (source database: Scopus).

in-line grating was reported in 1978 [46, 47], more and more scientific groups have devoted their research in such devices. In fact, the number of reported works related with vibrations using FBGs have grown significantly since 1994, (see Figure 19) although the first strain and temperature sensor was presented in 1988 [48, 49].

One of the most valuable properties of FBGs is their strong dependence of the resonance peak on very small variations of the Bragg period which makes them ideal for strain sensing $[48,49]$. They also have additional advantages, for example, their small size that makes them suitable to embed into composite materials [50] or concrete [51], or their dense wavelength multiplexing capability that makes possible multipoint sensing in complicated civil structures such as bridges or highways $[52,53]$. Also, this structure can be used to simultaneous measurement of several parameters such as temperature or humidity [54-60] and vibrations using wavelength multiplexing techniques.

4.1. Fiber Bragg Gratings: Working Principle. The optical properties of an FBG device arise from a series of partial reflectors arranged with a determined spatial period. In the optical fiber FBG, such reflectors are fabricated by altering the refractive index of the core of the optical fiber in a periodic manner, creating dielectric partial mirrors, and consequently a series of interferences occurs as the light travels through the device. In consequence, certain wavelengths which have a constant relation with the period of the refractive index perturbation experiment a strong transmission blockage. Such wavelengths are reflected by the FBG structure, while the device keeps unaltered the rest of the wavelengths, therefore the FBG acts as a wavelength selective reflector. This can be schematically seen in Figure 20.

Fiber bragg gratings are created by "inscribing" or "writing" the periodic variation of refractive index into the core of a special type of optical fiber using an intense ultraviolet (UV) source such as a UV laser [61-63]. A special germanium-doped silica fiber is used in the manufacture of FBG because it is photosensitive, and it is possible to induce refractive index shifts in areas exposed to strong UV radiation. Consequently, the FBGs are fabricated by exposing them to a very regular UV pattern. Such patterns 

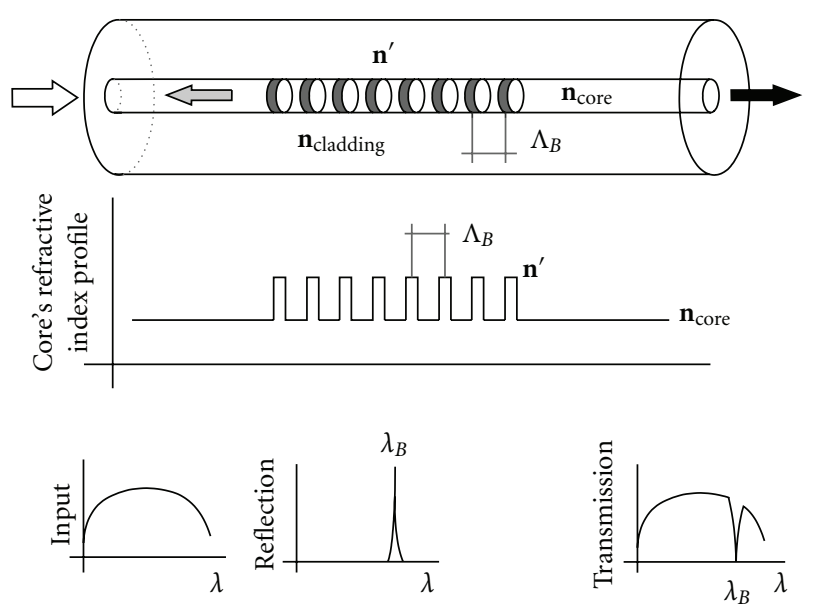

Figure 20: Schematic structure of a fiber bragg grating. The periodic variation of the core's refractive index causes the selective reflection of certain wavelengths, related with the FBG period.

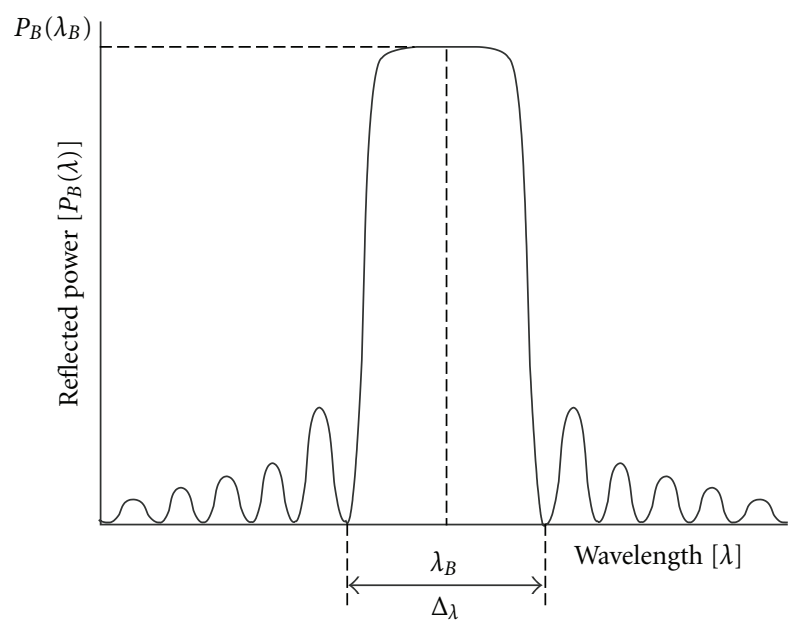

FIGURE 21: FBGs reflected power as a function of wavelength.

are obtained mainly by two different processes: interference and masking. The amount of the change in refractive index in the fiber core is a function of the intensity and duration of the UV light exposure.

While interference and masking are the most used techniques for fabricating FBGs, it is possible to write them point-by-point. Here, the laser has a narrow beam that is equal to the grating period. This method is specifically applicable to the fabrication of long-period fiber gratings and tilted gratings.

The fundamental principle behind the operation of a FBG is Fresnel reflection. Where light traveling between media of different refractive indices may both reflect and refract at the interface. The grating will typically have a sinusoidal refractive index variation over a defined length.

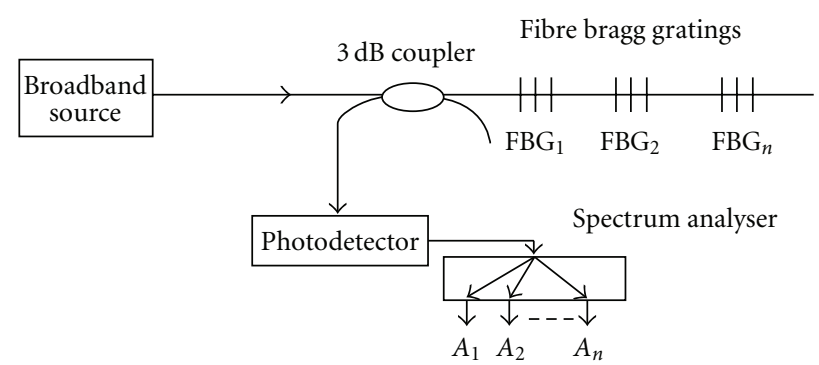

FIGURE 22: Experimental setup arranged for interrogating FBG multi-sensor systems using WDM. (Reproduced from [28] with Permission of Elsevier).

The wavelength spacing between the first minima (nulls), or the bandwidth $(\Delta \lambda)$, is given by

$$
\Delta \lambda=\left[\frac{2 \delta n_{0} \eta}{\pi}\right] \lambda_{B}
$$

where $\delta n_{0}$ is the variation in the refractive index $\left(n^{\prime}-n_{\text {core }}\right)$ (Figure 20) and $\eta$ is the fraction of power in the core. The typical reflectance response of an FBG is shown in Figure 21. A detailed description of FBG model can be found in [64].

Fiber bragg gratings can be used as direct sensing elements for strain, but also have uses in instrumentation applications such as seismology, pressure sensors for extremely harsh environment, and as downhole sensors in oil and gas wells for measurement of the effects of external pressure, temperature, seismic vibrations, and inline flow measurement.

One of the main advantages of FBG devices is their suitability for sensor network arrangements. It is not trivial to arrange multisensor setups, and other optical devices have strong limitations regarding the maximum number of sensors which can be integrated in an optical system (high intensity losses, etc.) In this sense, FBGs can be easily integrated in a multi-sensor arrangement, and the system can be interrogated using time-division multiplexing (TDM), frequency-division multiplexing (FDM), or wavelength-division multiplexing techniques (WDM) [28], using only one light source and a single detector system, which contribute to significantly lower the cost of the measuring system, see Figure 22.

4.2. FBG Vibration Sensing Applications. As it has been previously commented, the unique properties of FBG devices make them ideal for sensing magnitudes such as strain. In fact, the earliest sensing applications reported were strain and temperature $[48,49]$. Vibrations induce high-speed dynamic strain variations, and consequently the monitoring of the position of the resonance FBG wavelength allows measuring those vibrations. In vibration measuring applications, the bandwidth of the interrogation system is a key parameter that strongly limits the application range of the system. In order to reach high-speed interrogation rates of the FBG vibration sensors different approaches have been reported, but all of them avoid the optical spectral characterization of 


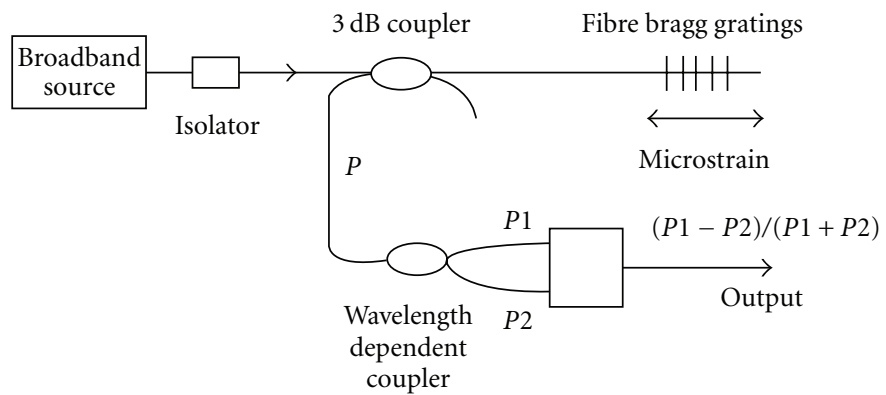

FIGURE 23: Strain and vibration measurement using an FBG sensor [28].

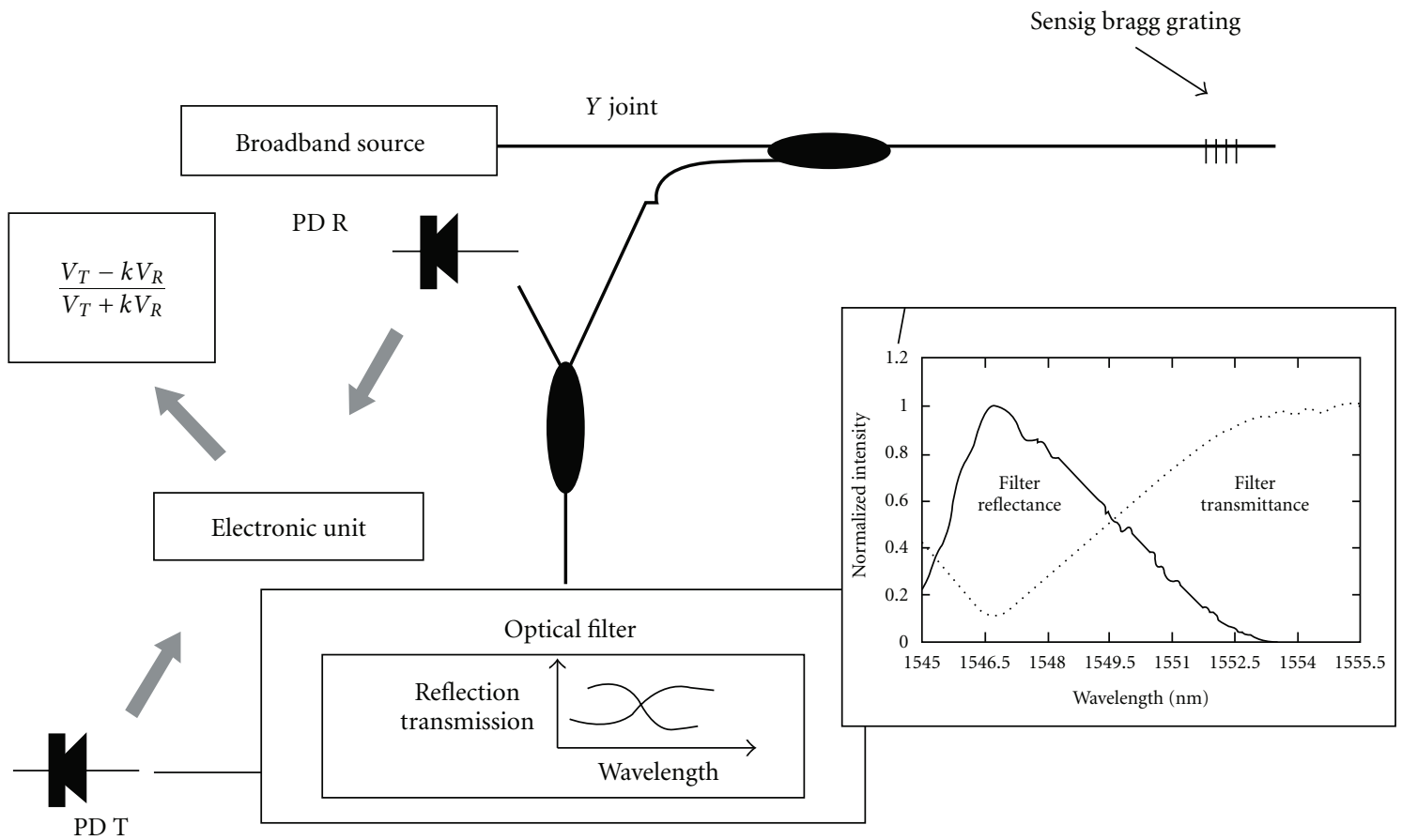

FIGURE 24: Experimental setup for dynamic strain with a single FBG [29].

the reflected light, since it takes some time and slows down the interrogation rate.

The most used optical setups for high-speed interrogation are based in splitting two or more different wavelength components of the reflected light from the FBG, combined with conventional intensity-based optoelectronic detectors. This passive differential light intensity measurement arrangement can reach interrogation speeds as high as $50 \mathrm{kHz}$ [28]. As it has been already exposed, when a FBG undergoes strain, the fiber bragg wavelength experiments a variation. A possible experimental setup for measuring this strain is a standard reflection setup shown in Figure 23, using broadband light source $[28,65]$. The reflected bragg signal returned via a $3 \mathrm{~dB}$ coupler is transmitted towards a wavelength-dependent coupler. Since the reflectivity of the FBG is being spectrally altered by the strain, therefore the signals coming from the wavelength dependent coupler will vary in intensity as the FBG is stretched. To measure those signals, it is possible to use of simple electronic processing to reveal the voltage directly proportional to the FBG strain. This electronic sensing stage makes possible high-speed interrogation rates. Other setups have been reported other than approaches where the wavelength selective device is replaced by an unbalanced Mach-Zender interferometer. One of its arms is phase-modulated via a ber-stretching piezoelectric device with detector feedback for phase drift compensation.

A similar approach was reported by Cusano and coworkers in [29]. The reflected light from an FBG sensor is selectively divided by an optical filter tuned with the bragg wavelength of the FBG, as it is shown in Figure 24. The reflected signal from the FGB sensor is then divided in two components by the optical filter, and consequently when the Bragg peak is displaced due to the strain the two measured components vary their relation with respect to the other.

This passive arrangement of the demodulation system, allows a full electronic interrogation; therefore, dynamic strain (vibrations) can be measured at high frequencies (up 


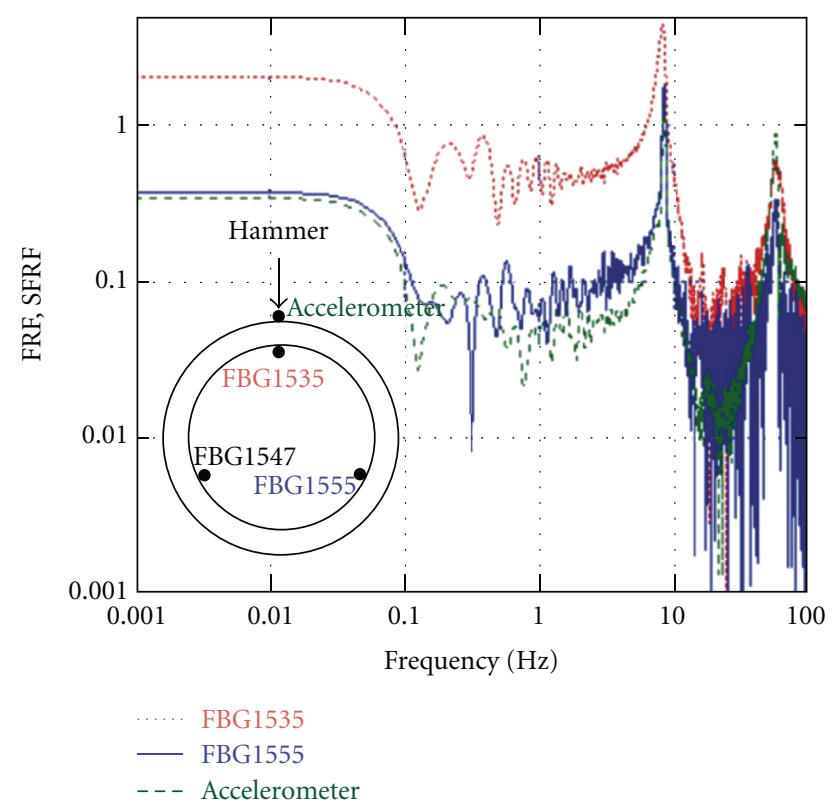

FIGURE 25: Response of a FBG seismic sensor [30].

to $400 \mathrm{kHz}$ [ [29]. In fact, the interrogation rate of these systems is only limited by the electronic measuring stage. This specific approach has been successfully applied to seismic measurement as it can be seen in Figure 25 [30]. In this work, three different FBG sensors were simultaneously interrogated and compared with a conventional accelerometer using the setup shown in Figure 24.

\section{Conclusions}

This paper has reviewed the main optical fiber sensor techniques for vibration measurement. An overview of the different techniques used in vibration sensors was presented. Intensity-based sensors were presented in first place, showing the setup used for vibration measurement. This type of sensors can be used both in reflection and transmission modes; however, the high dependence of the measurement accuracy to the source power level is a weak point of IBS in front of the other techniques presented in this paper. In contrast, Fabry-Pérot-based vibrometers are characterized by a better resolution and accuracy. Several setups can be achieved using this structure of sensor, for all these characteristics and advantages, the FPS is considered the most spread technique used to detect vibration in the optical fiber area. Finally, fiber bragg gratings vibrationsensing techniques have unique accuracy and wavelength multiplexing capacity. High-speed interrogation techniques are needed in order to detect high frequency oscillations. Finally, it is possible to say that optical fiber sensors can provide accuracy, durability, and economic configurations for vibration measurement, thus increasing the range of applications and opening new research fields.

\section{Acknowledgments}

The authors thank Dr. José Raúl Vento from the Pinar del Río University for his support and the Spanish Agency for International Development Cooperation (AECID) for the opportunity that it offers to scientific exchange between Spanish researchers and those from other countries.

\section{References}

[1] M. Lequime, "Fiber sensors for industrial applications," in Proceedings of the 12th International Conference on Optical Fibre Sensors, vol. 16 of OSA Technical Digest Series, pp. 6671, OSA, Washington, DC, USA, 1997.

[2] R. Medlock, "Fibre optics in process-control," Control Instrum, vol. 21, no. 4, pp. 105-108, 1989.

[3] V. Demjanenko, R. A. Valtin, M. Soumekh et al., "A noninvasive diagnostic instrument for power circuit breakers," IEEE Transactions on Power Delivery, vol. 7, no. 2, pp. 656-663, 1992.

[4] J. Dakin and B. Culshaw, Fiber Sensors: Principals and Components, vol. 1, Artech, Boston, Mass, USA, 1988.

[5] B. Culshaw and J. Dakin, Optical Fiber Sensors: Systems and Applications, vol. 2, Artech, Norwood, Mass, USA, 1989.

[6] T. G. Giallorenzi, J. A. Bucaro, A. Dandridge et al., "Optical fiber sensor technology," IEEE Journal of Quantum Electronics, vol. 18 , no. 4, pp. 626-665, 1982.

[7] D. A. Krohn, Fiber Optic Sensors: Fundamental and Applications, Instrument Society of America, Research Triangle Park, NC, USA, 1988.

[8] N. Lagokos, L. Litovitz, P. Macedo, and R. Mohr, "Multimode optical fiber displacement sensor," Applied Optics, vol. 20, p. 167,1981

[9] T. K. Gangopadhyay, "Prospects for Fibre Bragg gratings and Fabry-Perot interferometers in fibre-optic vibration sensing," Sensors and Actuators A, vol. 113, no. 1, pp. 20-38, 2004.

[10] J. R. Vento, L. l. Hernández, A. Santamaría, R. PérezJiménez, and J. A . Rabadán, "Infrared wireless DSSS system for indoor data communication links," in Optical Wireless Communications II, vol. 3850 of Proceedings of the SPIE, pp. 92-99, September 1999.

[11] R. Hongbin, J. Jinlei, C. Zhishe, and Z. Dengyu, Application of Spread Spectrum Technology to Measurement, Air Force Institute of Missile, Shaanxi, China, 1997.

[12] G. Perrone and A. Vallan, "A low-cost optical sensor for noncontact vibration measurements," IEEE Transactions on Instrumentation and Measurement, vol. 58, no. 5, pp. 16501656, 2009.

[13] B. Culshaw, Optical Fibre Sensing and Signal Processing, P. Pergrinus, London, UK, 1984.

[14] N. Aydin, T. Arslan, and D. R. S. Cumming, "A direct-sequence spread-spectrum communication system for integrated sensor microsystems," IEEE Transactions on Information Technology in Biomedicine, vol. 9, no. 1, pp. 4-12, 2005.

[15] G. D. Pitt, P. Extance, R. C. Neat et al., "Optical-fibre sensors," IETE Technical Review, vol. 3, no. 8, pp. 379-417, 1986.

[16] U. Gunasilan, "Operative factors contributing to the selection of fiber-optic techniques for remote measurement of strain/stress," in Proceedings of the IEEE 9th International Conference on Computer and Information Technology, Middlesex University Dubai, 2009.

[17] J. Hecht, Understanding Fiber Optics, Pearson Prentice Hall, NJ, USA, 2006. 
[18] W. Horsthuis and J. Fluitman, "Sensitivity dependence on number of bends in a microbend pressure sensor," NTGFachberichte, vol. 79, pp. 147-152, 1982.

[19] G. Murtaza, S. L. Jones, J. M. Senior, and N. Haigh, "Loss behavior of single-mode optical fiber microbend sensors," Fiber and Integrated Optics, vol. 20, no. 1, pp. 53-58, 2001.

[20] J. W. Berthold III, "Historical review of microbend fiber-optic sensors," Journal of Lightwave Technology, vol. 13, no. 7, pp. 1193-1199, 1995.

[21] M. Kuhn, "Curvature loss in singlemode fibres with lossy jacket," Archiv fur Elektronik und Ubertragungstechnik, vol. 29, no. 9, pp. 400-402, 1975.

[22] N. K. Pandey and B. C. Yadav, "Embedded fibre optic microbend sensor for measurement of high pressure and crack detection," Sensors and Actuators A, vol. 128, no. 1, pp. 33-36, 2006.

[23] S. Binu, V. P. Mahadevan Pillai, and N. Chandrasekaran, "Fibre optic displacement sensor for the measurement of amplitude and frequency of vibration," Optics and Laser Technology, vol. 39, no. 8, pp. 1537-1543, 2007.

[24] T. K. Gangopadhyay, S. Chakravorti, S. Chatterjee, and K. Bhattacharya, "Multiple fringe and nonsinusoidal signals obtained from a fiber-optic vibration sensor using an extrinsic Fabry-Perot interferometer," Measurement Science and Technology, vol. 16, pp. 1075-1082, 2005.

[25] S. Pullteap, H. C. Seat, and T. Bosch, "Modified fringecounting technique applied to a dual-cavity fiber Fabry-Perot vibrometer," Optical Engineering, vol. 46, no. 11, Article ID $115603,2007$.

[26] T. Yoshino, K. Kurosawa, K. Itoh, and T. Ose, "Fiberoptic Fabry-Perot Interferometer and its sensors applications," Journal of Quantum Electronics, vol. 18, no. 4, pp. 626-665, 1982.

[27] J. M. Corres, J. Bravo, F. J. Arregui, and I. R. Matias, "Unbalance detection in electrical engines using an in-line fiber etalon," in Proceedings of the 4th IEEE Conference on Sensors, pp. 1347-1350, Irvine, Calif, USA, November 2005.

[28] T. K. Gangopadhyay, "Prospects for Fibre Bragg gratings and Fabry-Perot interferometers in fibre-optic vibration sensing," Sensors and Actuators A, vol. 113, no. 1, pp. 20-38, 2004.

[29] A. Cusano, A. Cutolo, J. Nasser, M. Giordano, and A. Calabrò, "Dynamic strain measurements by fibre Bragg grating sensor," Sensors and Actuators A, vol. 110, no. 1-3, pp. 276-281, 2004.

[30] A. Laudati, F. Mennella, M. Giordano, G. D’Altrui, C. Calisti Tassini, and A. Cusano, "A fiber-optic Bragg grating seismic sensor," IEEE Photonics Technology Letters, vol. 19, no. 24, pp. 1991-1993, 2007.

[31] E. Abraham and S. D. Smith, "Nonlinear Fabry-Perot interferometers," Journal of Physics E, vol. 15, no. 1, article no. 004, pp. 33-39, 1982.

[32] G. Wild and S. Hinckley, "Acousto-ultrasonic optical fiber sensors: overview and state-of-the-art," IEEE Sensors Journal, vol. 8, no. 7, Article ID 4567505, pp. 1184-1193, 2008.

[33] D. A. Jackson, "Monomode optical fibre interferometers for precision measurement," Journal of Physics E, vol. 18, no. 12, article no. 001, pp. 981-1001, 1985.

[34] D. A. Jackson and J. D. C. Jones, "Fiber optic sensors," Optica Acta, vol. 33, no. 12, pp. 1469-1503, 1986.

[35] B. Culshaw, "Optical fiber sensor technologies: opportunities and-perhaps-pitfalls," Journal of Lightwave Technology, vol. 22, no. 1, pp. 39-50, 2004.

[36] F. J. Arregui, Y. Liu, I. R. Matias, and R. O. Claus, “Optical fiber humidity sensor using a nano Fabry-Perot cavity formed by the ionic self-assembly method," Sensors and Actuators B, vol. 59, no. 1, pp. 54-59, 1999.

[37] Y. Ge, M. Wang, and C. Yang, "A miniature extrinsic fiber Fabry-Perot pressure sensor based on fiber etching," in 20th International Conference on Optical Fibre Sensors, Proceedings of the SPIE, Edinburgh, UK, October 2009.

[38] J. S. Sirkis, D. D. Brennan, M. A. Putman, T. A. Berkoff, A. D. Kersey, and E. J. Friebele, "In-line fiber etalon for strain measurement,” Optics Letters, vol. 18, no. 22, pp. 1973-1975, 1993.

[39] R. O. Claus, M. F. Gunther, A. B. Wang, K. A. Murphy, and D. Sun, "Extrinsic Fabry Perot sensor for structural evaluations," in Applications of Fiber Optic Sensors in Engineering Mechanics, American Society of Civil Engineers, 1993.

[40] C. E. Lee and H. F. Taylor, "Interferometric optical fiber sensors using internal mirrors," Electronics Letters, vol. 24, no. 4, pp. 193-194, 1988.

[41] A. D. Kersey, T. A. Berkoff, and W. W. Morey, "Multiplexed fiber Bragg grating strain-sensor system with a fiber FabryPerot wavelength filter," Optics Letters, vol. 18, no. 16, pp. 1370-1372, 1993.

[42] A. M. Abdi and S. E. Watkins, "Strain sensor calibration using extrinsic Fabry-Perot interferometric sensors," Optical Engineering, vol. 46, no. 10, Article ID 104402, 2007.

[43] A. D. Kersey, D. A. Jackson, and M. Corke, "A simple fibre Fabry-Perot sensor," Optics Communications, vol. 45, no. 2, pp. 71-74, 1983.

[44] S. P. Christmas, D. A. Jackson, P. J. Henderson et al., "High-resolution vibration measurements using wavelengthdemultiplexed fibre Fabry-Perot sensors," Measurement Science and Technology, vol. 12, no. 7, pp. 901-905, 2001.

[45] Y.-J. Rao and D. A. Jackson, "Recent progress in fibre optic low-coherence interferometry," Measurement Science and Technology, vol. 7, no. 7, pp. 981-999, 1996.

[46] K. O. Hill, Y. Fujii, D. C. Johnson, and B. S. Kawasaki, "Photosensitivity in optical fiber waveguides: application to reflection filter fabrication," Applied Physics Letters, vol. 32, pp. 647-649, 1978.

[47] B. S. Kawasaki, K. O. Hill, D. C. Johnson, and Y. Fujii, "Narrow-band bragg reflectors in optical fibers," Optics Letters, vol. 3, no. 2, pp. 66-68, 1978.

[48] G. Meltz, W. W. Morey, W. H. Glenn, and J. D. Farina, "In-fiber Bragg-grating temperature and strain sensors," in Proceedings of the 34th International Instrumentation Symposium, pp. 239242, May 1988.

[49] G. Meltz, W. W. Morey, W. H. Glenn, and J. D. Farina, "Infiber bragg-grating sensors," in Proceedings of the Optical Fiber Sensors, vol. 2, pp. 163-166, 1988.

[50] J. Leng and A. Asundi, "Structural health monitoring of smart composite materials by using EFPI and FBG sensors," Sensors and Actuators A, vol. 103, no. 3, pp. 330-340, 2003.

[51] K.-T. Lau, L. Yuan, L.-M. Zhou, J. Wu, and C.-H. Woo, "Strain monitoring in FRP laminates and concrete beams using FBG sensors," Composite Structures, vol. 51, no. 1, pp. 9-20, 2001.

[52] Y. B. Lin, C. L. Pan, Y. H. Kuo, K. C. Chang, and J. C. Chern, "Online monitoring of highway bridge construction using fiber Bragg grating sensors," Smart Materials and Structures, vol. 14, no. 5, pp. 1075-1082, 2005.

[53] P. Moyo, J. M. W. Brownjohn, R. Suresh, and S. C. Tjin, "Development of fiber Bragg grating sensors for monitoring civil infrastructure," Engineering Structures, vol. 27, no. 12, pp. 1828-1834, 2005.

[54] X. Chen, K. Zhou, L. Zhang, and I. Bennion, "Simultaneous measurement of temperature and external refractive index by 
use of a hybrid grating in D fiber with enhanced sensitivity by HF etching," Applied Optics, vol. 44, no. 2, pp. 178-182, 2005.

[55] T. L. Lowder, R. H. Selfridge, and S. M. Schultz, "Surface relief D-fiber Bragg gratinas for high-temperature and multidimensional bend sensing," Materials Evaluation, vol. 65, no. 10, pp. 1042-1047, 2007.

[56] X. Chen, K. Zhou, L. Zhang, and I. Bennion, "Optical chemsensor based on etched tilted bragg grating structures in multimode fiber," IEEE Photonics Technology Letters, vol. 17, no. 4, pp. 864-866, 2005.

[57] E. R. Lyons and H. P. Lee, "Demonstration of an etched cladding fiber Bragg grating filter with reduced tuning force requirement," IEEE Photonics Technology Letters, vol. 11, no. 12, pp. 1626-1628, 1999.

[58] Y.-S. Yu, Z.-Y. Zhao, Z.-C. Zhuo, W. Zheng, Y. Qian, and Y.S. Zhang, "Bend sensor using an embedded etched fiber Bragg grating," Microwave and Optical Technology Letters, vol. 43, no. 5, pp. 414-417, 2004.

[59] A. Iadicicco, A. Cusano, S. Campopiano, A. Cutolo, and M. Giordano, "Thinned fiber Bragg gratings as refractive index sensors," IEEE Sensors Journal, vol. 5, no. 6, pp. 1288-1294, 2005.

[60] B. Sutapun, M. Tabib-Azar, and A. Kazemi, "Pd-coated elastooptic fiber optic Bragg grating sensors for multiplexed hydrogen sensing," Sensors and Actuators B, vol. 60, no. 1, pp. 27-34, 1999.

[61] K. O. Hill and G. Meltz, "Fiber Bragg grating technology fundamentals and overview," Journal of Lightwave Technology, vol. 15, no. 8, pp. 1263-1276, 1997.

[62] I. Del Villar, M. Achaerandio, I. R. Matías, and F. J. Arregui, "Deposition of overlays by electrostatic self-assembly in longperiod fiber gratings," Optics Letters, vol. 30, no. 7, pp. 720722, 2005.

[63] M. Achaerandio, F. J. Arregui, I. R. Matías, and R. O. Claus, "Electrostatic self-assembled thin films deposited on optical fiber long-period gratings for the fabrication of chemical sensors," in 2nd European Workshop on Optical Fibre Sensors, vol. 5502 of Proceedings of SPIE, pp. 300-303, 2004.

[64] I. Del Villar, I. R. Matias, and F. J. Arregui, "Long-period fiber gratings with overlay of variable refractive index," IEEE Photonics Technology Letters, vol. 17, no. 9, pp. 1893-1895, 2005.

[65] M. A. Davis and A. D. Kersey, "All-fibre Bragg grating strainsensor demodulation technique using a wavelength division coupler," Electronics Letters, vol. 30, no. 1, pp. 75-77, 1994. 

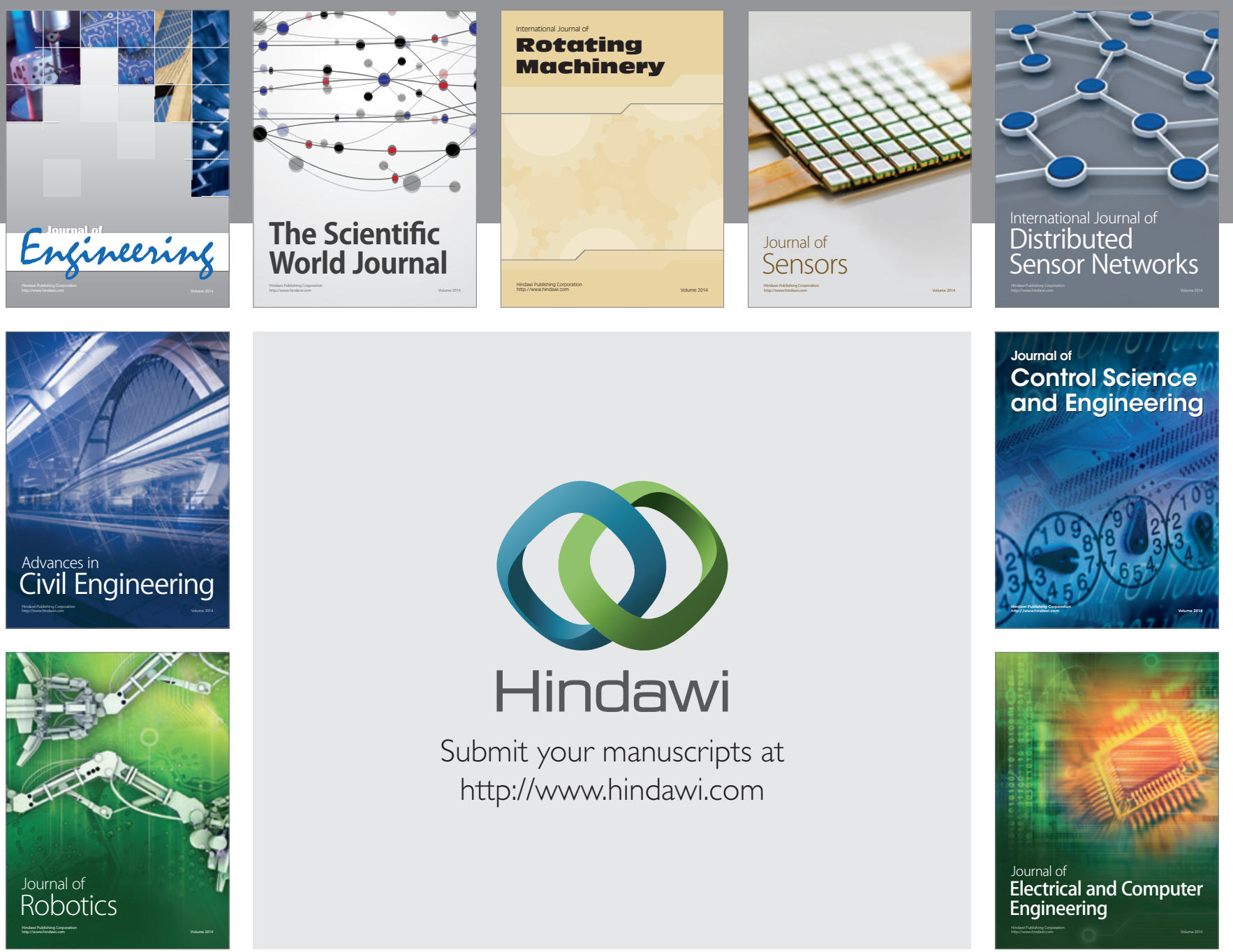

Submit your manuscripts at

http://www.hindawi.com
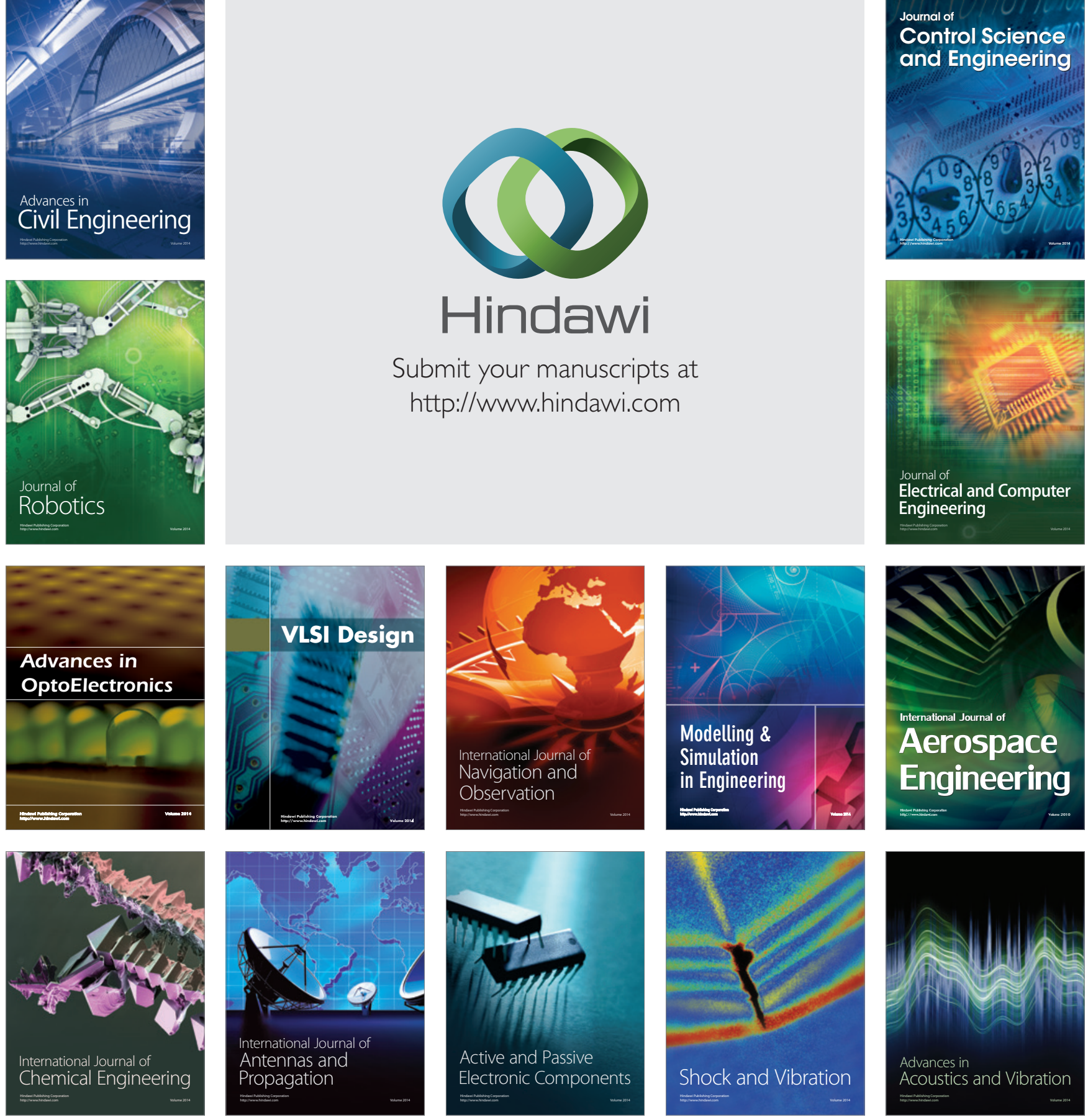